

ÁREA TEMÁTICA: RESÍDUOS SÓLIDOS

\title{
COMPARATIVO ENTRE ATERRO SANITÁRIO E INCINERAÇÃO - UM ESTUDO USANDO O MÉTODO PRESSÃO, ESTADO E RESPOSTA (PER)
}

Maria Clara Gonçalves Santos - goncalvesantos.clara@ hotmail.com

Instituto Federal da Bahia - Campus Vitória da Conquista

Roberta Rodrigues de Albuquerque-robertaalb14@gmail.com

Instituto Federal da Bahia - Campus Vitória da Conquista

Isabela Santos Aragão - aragaoisabelaeamb@ hotmail.com

Instituto Federal da Bahia - Campus Vitória da Conquista

Lucas Dias Costa- lucasdc1995@gmail.com

Instituto Federal da Bahia - Campus Vitória da Conquista 




\section{RESUMO}

Os resíduos sólidos são considerados o aparecimento mais visível e concreto da poluição ambiental, ocupando um importante papel na estrutura de saneamento de uma comunidade urbana e, consequentemente, nos aspectos relacionados à saúde pública. Observa-se que esta temática está inserida em uma área de estudo importante, juntamente com a identificação dos resíduos, destinação adequada, práticas de controle de geração de Resíduos Sólidos Urbanos (RSU), entre outras. No presente trabalho, foi aplicado o método pressão-estado-resposta de forma quanti-qualitativa e descritiva, com a finalidade de analisar os diferentes impactos ambientais gerados pelas duas formas de destinação final de resíduos sólidos e o grau de significância de cada um. Dessa maneira obteve-se o seguinte conjunto de indicadores de pressão para ambas as formas: alteração da qualidade dos recursos hídricos, do solo, da qualidade do ar e na saúde humana. E para cada indicador, descreveu seu estado e a resposta ao impacto. Sendo assim, verificou-se através da soma dos resultados, qual o método de destinação final de resíduos sólidos mais adequada quanto ao meio ambiente e saúde humana.

Palavras-chave: Resíduos sólidos, indicadores ambientais, Pressão-Estado-Resposta.

\section{INTRODUÇÃO/OBJETIVO}

O crescimento urbano desenfreado, seja ele devido ao aumento da taxa de natalidade, da atividade industrial ou ao inchaço no setor de construção civil, está diretamente relacionado ao aumento da geração de resíduos e/ou rejeitos sólidos, causando diversos problemas ambientais, como, por exemplo, degradação e esgotamento dos recursos naturais, além da disposição exacerbada e gerenciamento inadequados dos resíduos.

Segundo estudo realizado pela Associação Brasileira de Empresas de Limpeza Pública e Resíduos Especiais, das 72,5 milhões de toneladas de resíduos urbanos - RSU coletadas no ano de 2016, aproximadamente, 58,7\% tiveram destinação final correta, ou seja, foram depositadas em aterros sanitários; entretanto, 30 milhões de toneladas foram dispostos em lixões ou aterros controlados, isto é, lugares que não possuem o conjunto de sistemas e medidas necessários para proteção do meio ambiente contra danos e degradações. 




Entretanto, apesar de pouco mais da metade dos resíduos gerados receberem destinação correta, diversos impactos ambientais ainda podem ser gerados quando não há esse cuidado, como a contaminação do solo, das águas superficiais e subterrâneas pelo chorume, líquido gerado pela decomposição da matéria orgânica presente no RSU; e a acumulação no subsolo de gases tóxicos, asfixiantes e explosivos e seu eventual lançamento na atmosfera, bem como, a poluição do ar através da emissão de partículas e outros poluentes atmosféricos diretamente liberados pela queima de resíduos ou através da incineração de materiais sem o uso de equipamentos de controle adequados (GOUVEIA, 2012).

Faz-se necessário, portanto, o uso de ferramentas que auxiliem na análise das diversas variáveis que influenciam nos processos de degradação ambiental, ocasionados pela disposição de resíduos gerados pela população, sejam amplamente estudadas e aplicadas às realidades de cada localidade.

Os indicadores de sustentabilidade, por exemplo, que são importantes instrumentos de divulgação de ações sustentáveis, permitem analisar, objetivamente, as condições desejáveis, devendo ser capazes de mostrar tendências dos processos de desenvolvimento ao longo do tempo (HANAI \&ESPÍNDOLA, 2011).

Em estudos realizados por Lira \& Cândido (2008) e Hanai \&Espíndola (2011), constatou-se que, além dos modelos aplicados local e regionalmente, os modelos de indicadores de sustentabilidade aceitos internacionalmente e mais utilizados por outros autores são: Força Motriz-Estado-Resposta (FER); Pegada Ecológica; Modelo Painel de Sustentabilidade; Barômetro da Sustentabilidade; e Modelo Pressão-Estado-Resposta (PER).

Este baseia-se na pressão exercida pelas atividades humanas sobre o ambiente, alterando a qualidade e a quantidade de recursos naturais, ou seja, alterando o seu estado. Em contrapartida, através de políticas ambientais, econômicas ou setoriais, a sociedade pode responder a essas mudanças efetivamente (LIRA \& CÂNDIDO, 2008).

Neste trabalho, que tem por objetivo fazer um comparativo entre dois tipos de destinação final de resíduos sólidos urbanos, aterro sanitário e incineração, será utilizado o Modelo Pressão-Estado-Resposta para identificar e qualificar os impactos ambientais gerados pelas duas formas de descarte, bem como, propor alternativas para a mitigação dos mesmos.

\section{METODOLOGIA}






Para realização do presente trabalho, utilizou-se o método PRESSÃO-ESTADORESPOSTA (PER) aplicado de forma quanti-qualitativa e descritiva a fim de sintetizar os indicadores ambientais utilizados para comparar dois tipos de destinação final de resíduos sólidos urbanos: aterro sanitário e incineração.

Primeiramente foi feito um levantamento dos possíveis impactos ambientais dos dois tipos de destinação final, o que define os indicadores de pressão, em seguida, foi apontado como cada impacto posteriormente identificado afeta de forma negativa o indivíduo, bem como a qualidade do ambiente, definindo os indicadores de estado. Por fim, foram propostas para cada um dos impactos citados, medidas mitigadoras, como à adesão de programas ambientais e por fim, como seria à possível resposta da sociedade para cada medida de melhoria ambiental adotada, o que caracteriza os indicadores de resposta.

A fim de quantificar o grau de importância de cada pressão, estado e resposta criou-se uma tabela para atribuição de "notas" aos indicadores, as quais foram elaboradas com o intuito de uma maior aproximação dos indicadores à realidade. Atribuiu-se aos indicadores de pressão e estado, notas negativas, visto que a pressão é considerada como a ação antrópica negativa ao meio e o estado como consequência do impacto (redução da qualidade ambiental). Para balancear a condição do meio em resposta as atribuições negativas de pressão e estado, foram atribuídas notas positivas as ações mitigadoras.

Obedecendo a negatividade das notas de pressão e estado atribuiu-se valores graduais variando em 4 diferentes escalas, considerando zero, como a melhor nota e 5 como a pior (tabela 1). Já os valores de resposta foram elaborados seguindo a pressuposição que as ações públicas (respostas) são aplicadas dependendo da situação em que o meio se encontra, considerado este, a resultante do decaimento da qualidade ambiental (estado) devido à ação antrópica (pressão), ou seja, as notas atribuídas à resposta dependem especificamente da soma das notas de pressão e estado. (RIBEIRO, 2012)

Tabela 1 - Notas atribuídas no modelo PER

\begin{tabular}{|l|l|l|}
\hline \multicolumn{1}{|c|}{ Pressão (-) } & \multicolumn{1}{c|}{ Estado (-) } & \multicolumn{1}{c|}{ Resposta (+) } \\
\hline $\mathbf{5}$ - Alta pressão & $\mathbf{5}$ - Altamente negativa & $\mathbf{1 0}$ - Muito boa \\
$\mathbf{3}$ - Forte pressão & $\mathbf{3}$ - Negativa & $\mathbf{5}$ - Boa \\
$\mathbf{2}-$ Fraca pressão & $\mathbf{2}$ - Sensível & $\mathbf{3}$ - Fraca \\
$\mathbf{0}-$ Sem pressão & $\mathbf{0}$ - Positiva & $\mathbf{0}$ - Insatisfatória \\
\hline
\end{tabular}




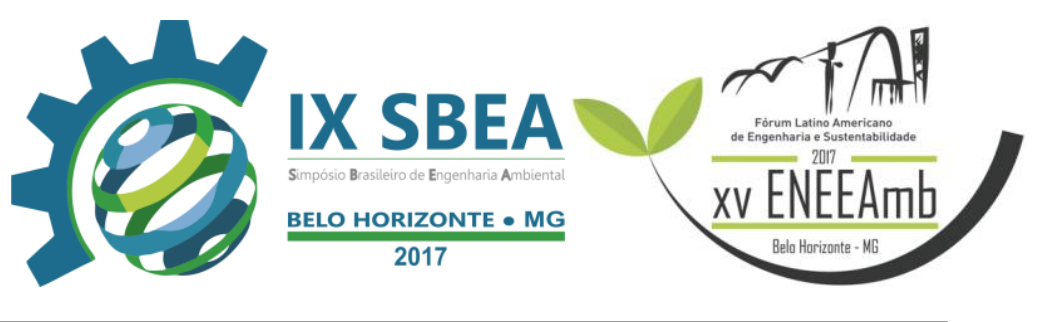

Com as atribuições das notas acima, elaborou-se uma fórmula (Equação 1) que possibilitou calcular qual é o tipo de destinação final de RSU menos impactante ao meio ambiente.

$$
\sum=\text { Resposta }+(- \text { Pressão+(-Estado)) (Equação 1) }
$$

Obtido o valor da equação para aterro sanitário e incineração foi feita a comparação e escolhido qual das duas formas de destinação final causaria impactos menos significativos para o meio, ou seja, a mais adequada. Os resultados foram divididos em tópicos para melhor compreensão dos mesmos. Algumas tabelas para sintetizar os resultados foram elaboradas com o auxílio do Excel.

\section{RESULTADOS E DISCUSSÃO}

\section{Incineração}

\subsection{Alteração da qualidade dos recursos hídricos (superficiais e subterrâneos):}

As cinzas resultantes do processo de incineração (mistura de metais pesados e produtos químicos) apresentam alta toxicidade, quando manejadas e depositadas de forma inadequada, elas representam riscos para a saúde e o meio ambiente. Em razão do processo de lixiviação desencadeado pelas chuvas, os lençóis freáticos, rio e mananciais próximos de onde essas cinzas foram depositadas de forma inadequada podem sofrer uma séria contaminação pelos derivados químicos provenientes. Para minimizar os riscos, têm-se a disposição adequada das cinzas como melhor medida mitigadora, juntamente com a prática das legislações vigentes.

1.2. Alteração da qualidade do solo: Quando manejadas e depositadas de forma inadequada no meio ambiente, as cinzas oriundas do processo de incineração que apresentam alto teor de toxicidade, poderão ser retidos pelos solos e assimilados pelos vegetais, não sendo recomendada, deste modo, a utilização de culturas para alimentação. A destinação final de forma segura e ambientalmente correta dessas cinzas é a solução para a problemática, juntamente com a prática das legislações vigentes.

1.3. Alteração da qualidade do ar: As emissões tóxicas, oriundas dos incineradores possuem três tipos de poluentes perigosos para o ambiente e para a saúde humana: os metais pesados, os produtos de combustão incompleta e as substâncias químicas 


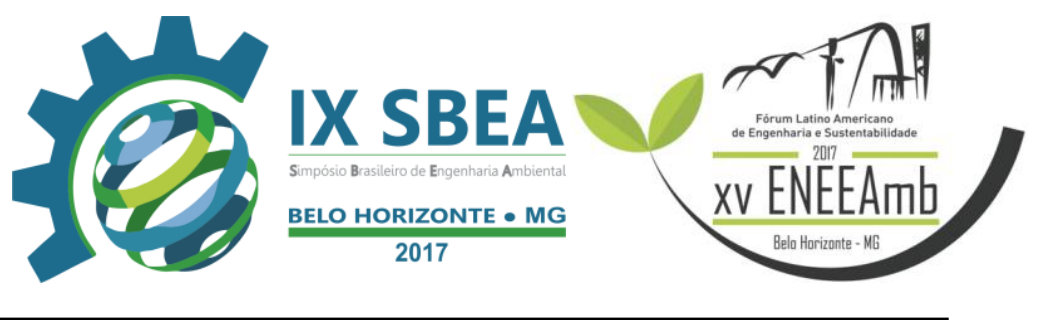

novas formadas durante o processo de incineração. Alguns metais pesados provenientes da incineração como chumbo, cádmio, arsênio, mercúrio e cromo, não são destruídos durante o processo, sendo liberados para o ambiente em formas até mais concentradas e perigosas do que no resíduo original. Têm-se ainda a formação de produtos químicos altamente tóxicos durante o processo de combustão - as dioxinas e os furanos - produtos químicos mais tóxicos já conhecidos. Sugere-se o uso de equipamentos de controle de poluição como o lavador de gases, que podem remover alguns desses metais das emissões, juntamente com a medição no mínimo anual de dioxinas e furanos, bem como de metais pesados. Bem como o atendimento das legislações vigentes.

1.4. Alterações na saúde humana: Através de estudos realizados por especialistas da área, relaciona-se a exposição do ser humano a metais pesados, a organoclorados e a outros poluentes liberados por incineradores diretamente com o aumento das taxas de câncer, doenças respiratórias, anomalias reprodutivas (como má formação fetal), danos neurológicos e a outros efeitos sobre a saúde. Para os funcionários de locais com incineradores, recomendase o uso de EPI (equipamentos de proteção individual) e EPC (equipamentos de proteção coletiva), para a empresa de incineração o cumprimento da legislação em vigência, a Resolução CONAMA no 316 de 29 de outubro de 2002, que "dispõe sobre procedimentos e critérios para o funcionamento de sistemas de tratamento térmico de resíduos" (BRASIL, 2002).

\section{Aterro Sanitário}

2.1. Alteração da qualidade dos recursos hídricos (superficiais e subterrâneos): A má disposição dos resíduos sólidos gera diversos impactos oriundos de poluição para o meio ambiente, dentre as principais fontes de poluição, têm-se o chorume gerado no processo de degradação da matéria orgânica. Quando despejado nos cursos d'água superficiais, pode alterar a DBO e DQO da água, influenciando negativamente na fauna e flora macro e microscópica. Ao atingir os aquíferos pode poluir poços e causar endemias caso contenha organismos patogênicos (MATOS, 2011). Sugere-se a implementação do tratamento de chorume bem como a de um programa de monitoramento sistemático tantos dos recursos superficiais quanto subterrâneos. 


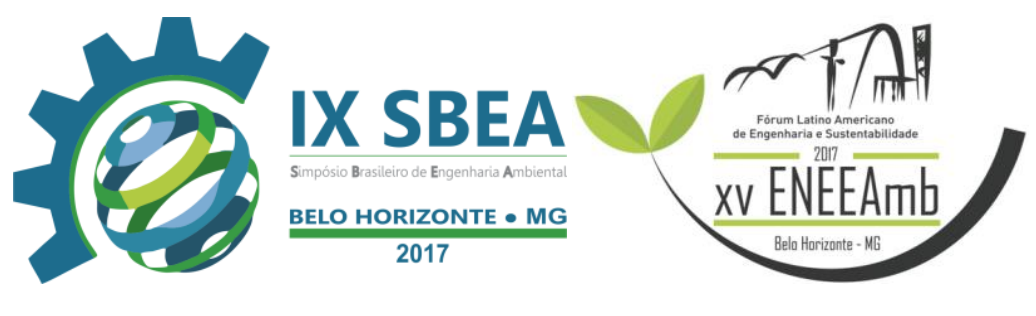

2.2. Alteração da qualidade do solo: A disposição irregular dos resíduos sólidos pode ocasionar a poluição do solo por metais pesados e compostos orgânicos tóxicos provenientes da decomposição dos resíduos. Vale ressaltar que muitas substâncias contidas nos resíduos urbanos são corrosivas para alguns materiais de construção e apresentam risco de explosões devido ao acumulo de gases mesmo após anos, inviabilizando a urbanização na área (SISINNO, 2002). Sugere-se como medida minimizadora, a disposição adequada desses resíduos, caso esse acondicionamento for em um aterro, recomenda-se a impermeabilização do solo, e ainda a drenagem de gases e chorume.

2.3. Alteração da qualidade do ar: Os principais impactos decorrentes da disposição inadequada dos resíduos sólidos que alteram a qualidade do ar estão relacionados a produção de gases poluentes e material particulado. Para LIMA (1995), o processo de decomposição dos resíduos sólidos por meio da ação dos microrganismos, produz o biogás que é composto por hidrogênio, nitrogênio, gás sulfídrico dióxido de carbono e metano. Este último é altamente inflamável e junto com o ar pode formar uma mistura explosiva; por isso é comum a combustão espontânea do lixo em vazadouros a céu aberto. Cabe ressaltar que o metano e o dióxido de carbono contribuem para a intensificação do Efeito Estufa (SISINNO, 2002). Para esses impactos, têm-se como medida mitigadora a efetivação da fiscalização para combater as ações irregulares e implantação de um programa de monitoramento da qualidade do ar, juntamente com o cumprimento da legislação vigente.

2.4. Alterações na saúde humana: A coleta informal de materiais recicláveis expõe os trabalhadores a situações de extremo risco. Gases resultantes da decomposição dos resíduos sólidos como o metano é apontado como um poluente prejudicial ao homem, podendo, em alguns casos, provocar câncer, náusea, sonolência ou irritação nas narinas e olhos. Além disso, há proliferação de vetores como moscas, baratas e ratos, transmissores de doenças. Sugere-se como suporte à criação e/ou fortalecimento das cooperativas de resíduos sólidos atuantes na área e capacitação dos catadores para diminuir os riscos de contaminação e acidentes eventuais.

\section{Comparações finais}

Com os dados para preparação da tabela PER (impacto, consequências do impacto e medidas mitigadoras) obtidos acima, devidamente tabulados, foram atribuídas as notas de 


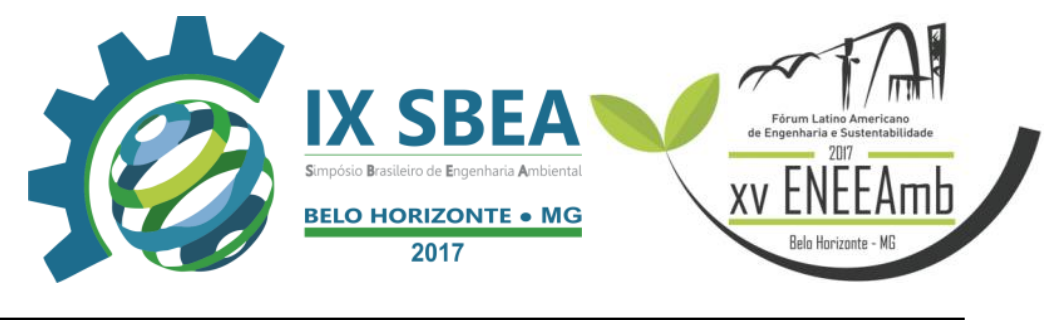

cada indicador (pressão, estado e resposta) e em seguida, o somatório foi realizado através da Equação 1. Os resultados obtidos foram dispostos em duas tabelas, destinação final em incineração(Tabela 2) e para aterro sanitário (Tabela 3). Com os somatórios, foi possível comparar e deliberar sobre qual método de destinação final de RSU de acordo o modelo de PER é mais indicado por agir de forma menos impactante no meio ambiente.

Tabela 2 - Notas atribuídas e os valores dos somatórios para destinação final do tipo incineração

\begin{tabular}{|c|c|c|c|}
\hline PRESSÃO (-) & ESTADO (-) & RESPOSTA (+) & $\sum$ \\
\hline-5 & -5 & 5 & -5 \\
\hline-5 & -5 & 3 & -7 \\
\hline-5 & -5 & 10 & 0 \\
\hline-5 & -5 & 3 & -7 \\
\hline \multicolumn{3}{|c|}{ TOTAL } \\
\hline
\end{tabular}

Tabela 3 - Notas atribuídas e os valores dos somatórios para destinação final do tipo aterro sanitário

\begin{tabular}{|c|c|c|c|}
\hline PRESS ̃̃O (-) & ESTADO (-) & RESPOSTA (+) & $\sum$ \\
\hline-3 & -3 & 10 & 5 \\
\hline-3 & -2 & 5 & 0 \\
\hline-2 & -3 & 10 & 5 \\
\hline-3 & -2 & 3 & 7 \\
\hline \multicolumn{3}{|c|}{ TOTAL } \\
\hline
\end{tabular}




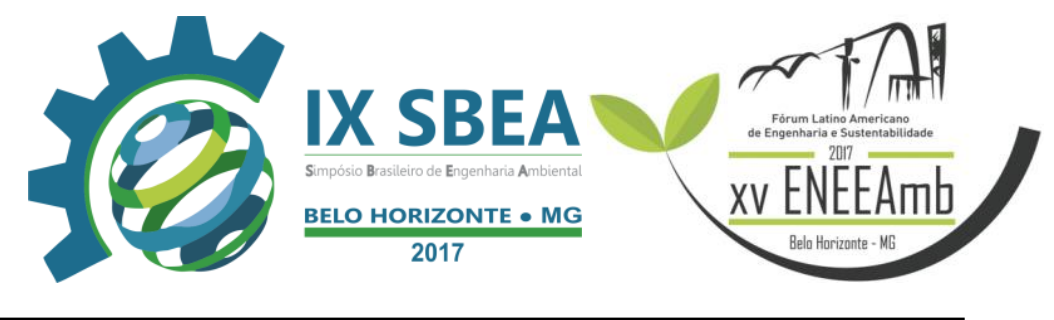

\subsection{Gráficos comparativos}

Gráfico 1 - Gráfico comparativo do Indicador de Pressão Incineração X Aterro Sanitário

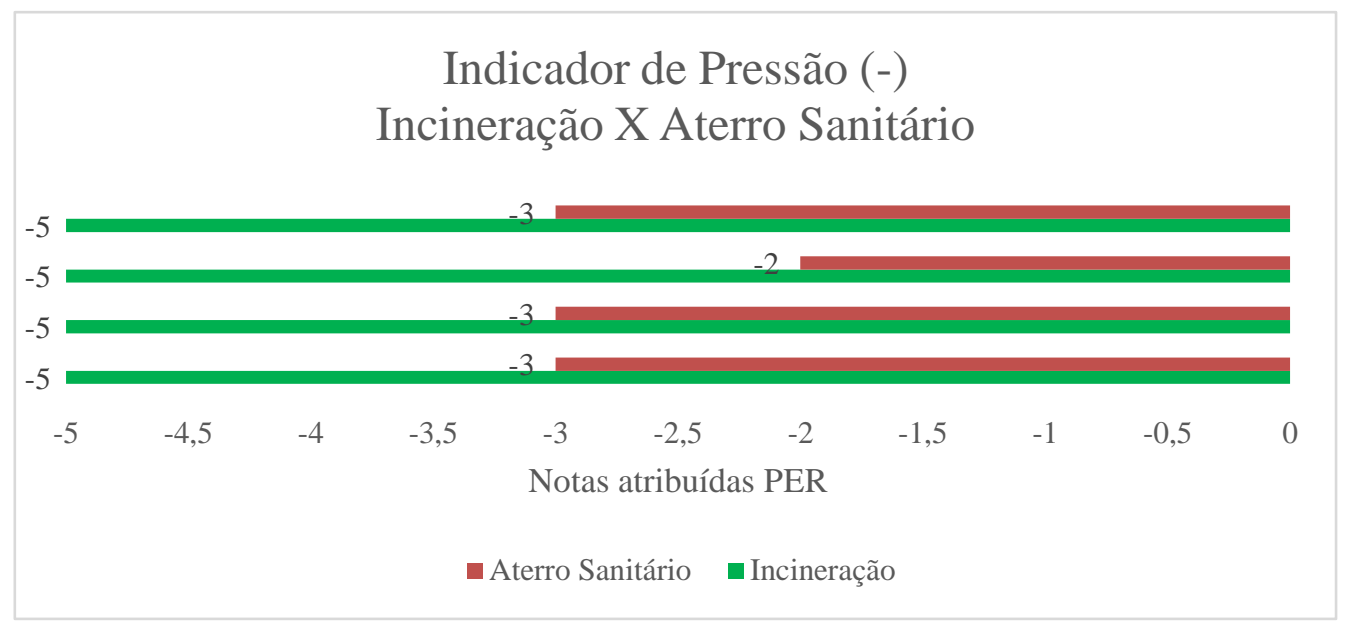

Gráfico 2 - Gráfico comparativo do Indicador de Estado Incineração X Aterro Sanitário

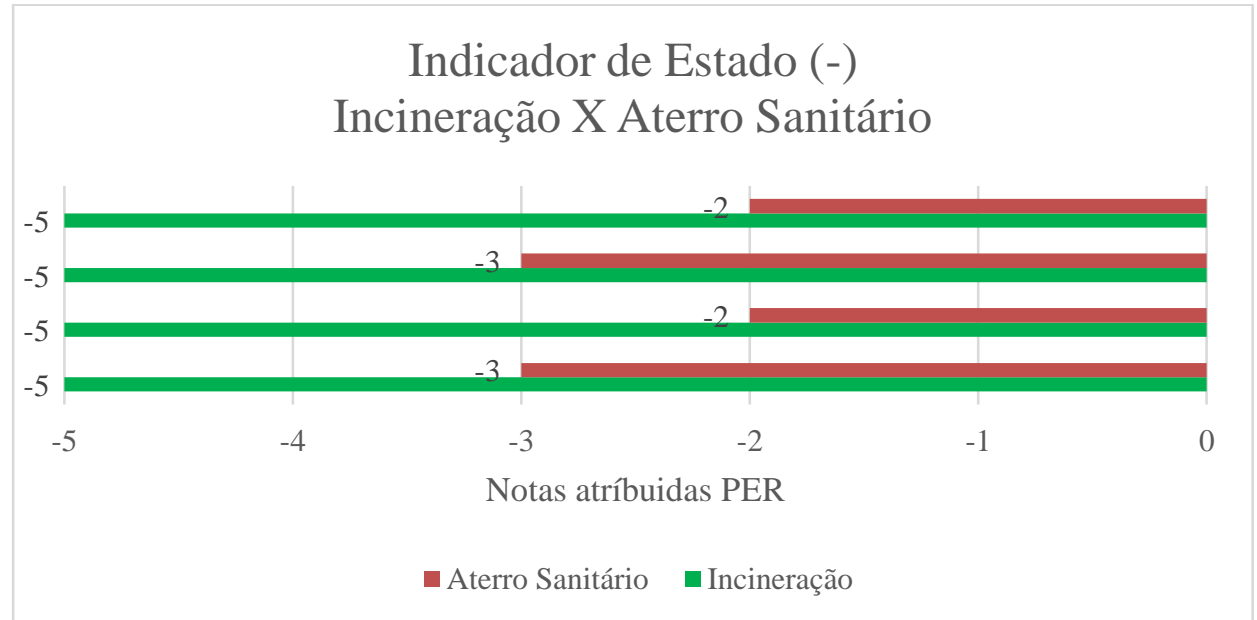

Gráfico 3- Gráfico comparativo do Indicador de Pressão Incineração X Aterro Sanitário 

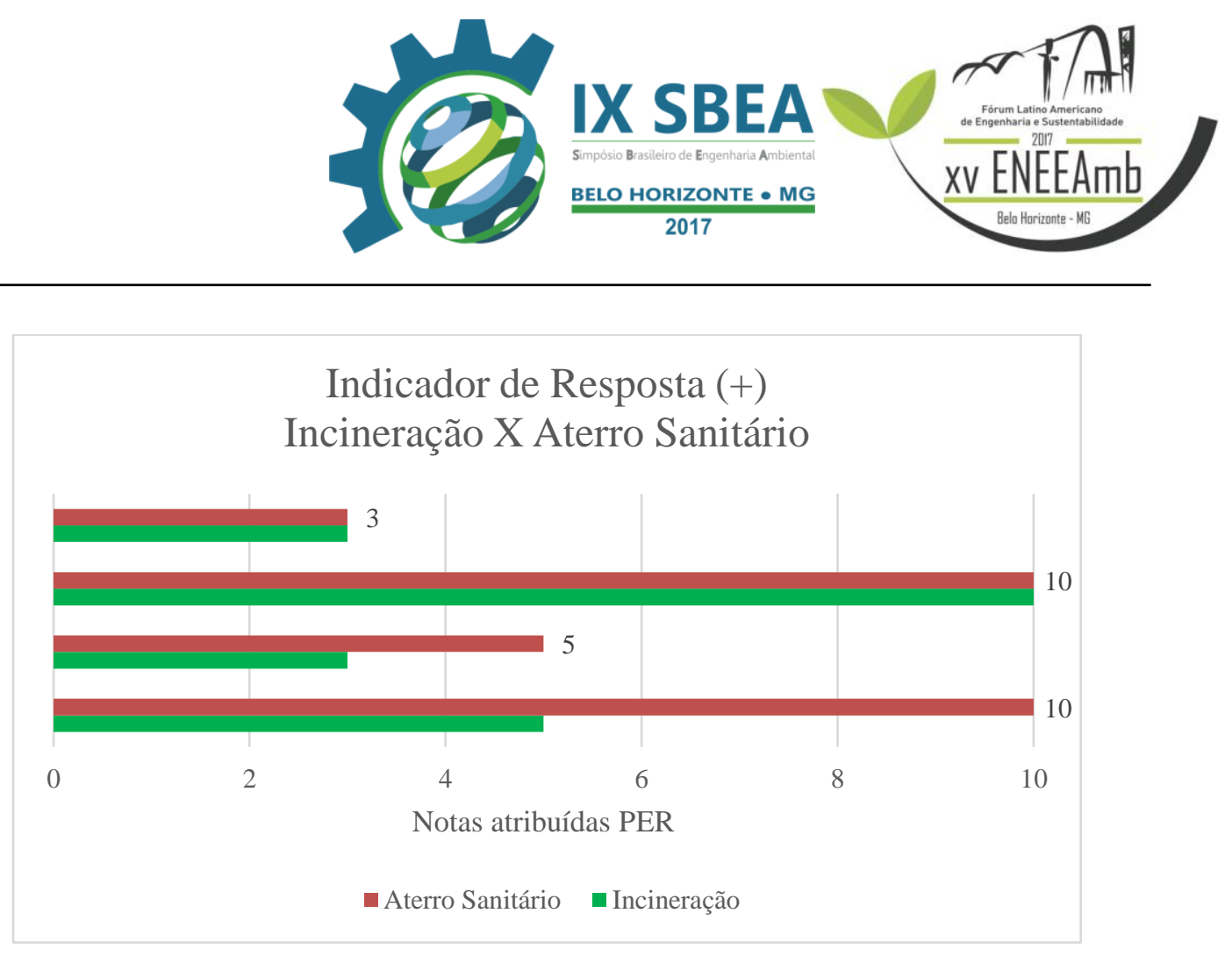

\section{CONCLUSÕES/RECOMENDAÇÕES}

A partir da análise dos resultados e discussão apresentados acima, pode-se concluir que a forma de destinação final de RSU mais adequada e menos impactante ao meio ambiente é a de aterro sanitário, esta mostrou-se como uma destinação final sanitária adequada e completa, enquanto as pressões da incineração receberam a nota -5 (alta pressão), as do aterro sanitário receberam notas -3 e -2 (forte e fraca pressão) respectivamente, o que indica impactos menos significativos para o meio advindos do aterro sanitário. As respostas também foram mais positivas para o aterro sanitário do que para a incineração.

Por fim, ao realizar o somatório dos indicadores para a incineração (Tabela 2) obtevese um valor negativo (-19) muito inferior quando comparado ao valor positivo (7) obtido através da soma dos indicadores do aterro sanitário (Tabela 3). O que reforça as vantagens de uma forma de destinação final de RSU sobre a outra.

Observa-se que metodologia fornece informações relevantes para gestão ambiental, pois possibilita sua aplicação em qualquer lugar que esteja sendo acometido com problemas ambientais relacionados às ações antrópicas, é também um método relativamente abrangente e de fácil aplicabilidade.

\section{REFERÊNCIAS BIBLIOGRÁFICAS}




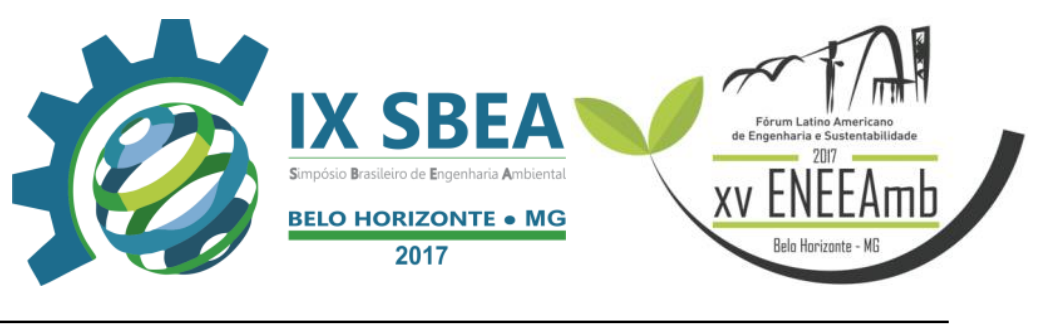

BARBOSA, Gisele Silva. O desafio do desenvolvimento sustentável. Revista Visões, v. 4, n. 1, p. 1-11, 2008.

BRASIL. Resolução CONAMA n 316, de 29 de outubro de 2002. Dispõe sobre procedimentos e critérios para o funcionamento de sistemas de tratamento térmico de resíduos. DOU n. 224, de 20 de novembro de 2002, Seção 1, páginas 92-95

GOUVEIA, Nelson. Resíduos sólidos urbanos: impactos socioambientais e perspectiva de manejo sustentável com inclusão social. Ciência \& Saúde Coletiva, v. 17, n. 6, p. 15031510, 2012.

HANAI, Frederico Yuri; ESPÍNDOLA, Evaldo Luiz Gaeta. Indicadores de sustentabilidade: conceitos, tipologias e aplicação ao contexto do desenvolvimento turístico local. Revista de Gestão Social e Ambiental, v. 5, n. 3, p. 135-149, 2011.

LIMA, Luiz Mário Queiroz. Lixo, tratamento e biorremediação. In: Lixo, tratamento e biorremediaçao. Hemus, 1995.

LIRA, Waleska Silveira; CÂNDIDO, Gesinaldo Ataíde. Análise dos modelos de indicadores no contexto do desenvolvimento sustentável. Perspectivas Contemporâneas, v. 3, n. 1, 2008.

MATOS, Francinaldo Oliveira et al. Impactos ambientais decorrentes do aterro sanitário da região metropolitana de Belém-PA: aplicação de ferramentas de melhoria ambiental. Caminhos de Geografia, v. 12, n. 39, 2011.

SISINNO, Cristina Lúcia Silveira. Destino dos resíduos sólidos urbanos e industriais no Estado do Rio de Janeiro: avaliação da toxicidade dos resíduos e suas implicações para o ambiente e para a saúde humana. 2002. Tese de Doutorado. Escola Nacional de Saúde Pública. 